\title{
El Cuerpo Lésbico Representado en India: sensacionalismo y voyerismo en la cultura popular contemporánea ${ }^{12}$
}

\author{
The Lesbian Body Represented in India: sensationalism and voyeurism \\ in contemporary popular culture
}

\author{
Antonia Navarro-Tejero \\ Universidad de Córdoba - España \\ fflnatea@uco.es
}

\section{Resumen}

En este artículo trataremos de ilustrar cómo Strange Obsession (1992) y Girlfriend (2004) pretenden construir unos espacios imaginativos lésbicos, argumentando que ambos trabajos comparten unas estrategias de marketing con éxito a la vez que manifiestan conceptualizaciones tradicionales sobre el género $\mathrm{y}$ modelos heteronormativos sobre la identificación de las mujeres.1 La aclamada escritora (heterosexual) Shobha Dé publicó la novela Strange Obsession, donde muestra una carencia de sensibilidad hacia el tema de la representación de la homosexualidad femenina. Doce años después, Girlfriend, una película del director y escritor también heterosexual Karan Razdan, ha suscitado muchos debates en torno a asuntos relacionados con la misma temática en India. Mientras el director-escritor declaraba que había producido el film porque entendía a las lesbianas, la mayoría de los activistas queer enfurecieron con la representación del lesbianismo como una condición patológica, una representación equivocada y grosera de la identidad queer basada en estereotipos que asociaban la homosexualidad con la criminalidad. La película ha sido etiquetada por muchos activistas LGBT como porno blando, y critican el acercamiento del escritor-director y su apoyo a las ideologías dominantes.

\begin{abstract}
This article will attempt to illustrate how Strange Obsession (1992) and Girlfriend (2004) intend to build lesbian imaginative spaces, arguing that both works share some successful marketing strategies, while they both adopt traditional gender conceptualizations and heteronormative models of women identification. The acclaimed writer (heterosexual) Shobha Dé published the novel Strange Obsession, which shows a lack of sensibility with regard to the issue of female homosexuality representation. Twelve years later, Girlfriend, by film director and writer Karan Razdan, also a heterosexual, has raised many debates on issues related this very subject in India. While the director-writer stated that he had produced the film because he understood lesbians, most queer activists got angry with the representation of lesbianism as a pathological condition, a gross misrepresentation of queer identity based on stereotypes that associate homosexuality with crime. The film has been labeled by many LGBT activists as a soft porn, and they criticize the approach of writer-director and his support for dominant ideologies.
\end{abstract}

Keywords: Movies; Body; Lesbians.

Palabras-clave: Películas; Cuerpo; Lesbianas. 
En este artículo trataremos de ilustrar cómo Strange Obsession (1992) y Girlfriend (2004) pretenden construir unos espacios imaginativos lésbicos, argumentando que ambos trabajos comparten unas estrategias de marketing con éxito a la vez que manifiestan conceptualizaciones tradicionales sobre el género y modelos heteronormativos sobre la identificación de las mujeres ${ }^{3}$. La aclamada escritora (heterosexual) Shobha Dé (1992) publicó la novela Strange Obsession, donde muestra una carencia de sensibilidad hacia el tema de la representación de la homosexualidad femenina. Doce años después, Girlfriend, una película del director $\mathrm{y}$ escritor también heterosexual Karan Razdan (2004), ha suscitado muchos debates en torno a asuntos relacionados con la misma temática en India. Mientras el directorescritor declaraba que había producido el film porque entendía a las lesbianas, la mayoría de los activistas queer enfurecieron con la representación del lesbianismo como una condición patológica, una representación equivocada y grosera de la identidad queer basada en estereotipos que asociaban la homosexualidad con la criminalidad. La película ha sido etiquetada por muchos activistas LGBT como porno blando, y critican el acercamiento del escritor-director y su apoyo a las ideologías dominantes. En una década, nada ha cambiado.

Ambos trabajos objeto de estudio en este artículo pueden categorizarse como pertenecientes a la cultura popular, ya que Girlfriend fue producida dentro de la industria Bollywood y Shobha Dé es autora de numerosos bestsellers, así como guionista de series de televisión indias populares, miembro de la alta sociedad, antigua supermodelo, columnista de renombre y diseñadora. Aunque ambos trabajos han sido reseñados como creaciones únicas por sus representaciones de las relaciones lésbicas, podemos incidir en que, más que desafiar y minar los modelos hegemónicos de representación de las mujeres lesbianas, Girlfriend y Strange Obsession despliegan, y manipulan para buscar un efecto dramático, un repertorio de estereotipos visuales/textuales que han sido asociados siempre dentro de la imaginación misógina y patriarcal con percepciones de las mujeres lesbianas como abyectos sexuales y de las relaciones heterosexuales como víctimas de su demencia.

Ambos textos culturales, Girlfriend y Strange Obsession, presentan a dos mujeres solteras que aspiran a ser modelos y son presa, en contra de su voluntad, de una relación tormentosa con sus mejores amigas en Mumbai, quienes son representadas como personajes varoniles paranoicos con una obsesión violenta hacia sus inocentes víctimas siempre que éstas intentan iniciar una relación heterosexual. En contra de este telón de fondo exótico, ambos triángulos amorosos construyen un continuum de roles: la chica inocente, femenina y vulnerable (Sapna en Girlfriend y Amrita en Strange Obsession), la lesbiana posesiva y sexualmente dominante - la única que es presentada como lesbiana y que parece tener un desorden obsesivo compulsivo - (Tanya en Girlfriend y Meenakshi en Strange Obsession), y el héroe masculino (Rahul en Girlfriend y Rakesh y anteriormente Karan y Partha en Strange Obsession). Al final, la lesbiana muere violentamente, de forma que la chica es liberada y puede vivir un matrimonio heterosexual feliz $y$ convencional.

En contra de estas reseñas y opiniones críticas, nosotros defenderemos que estos trabajos no propagan al lesbianismo como una alternativa sexual, ya que están reproduciendo una vez más el cliché patriarcal heterosexual. Y lo que es más, ambos repudian a sus protagonistas lesbianas al reducirlas a simples desequilibradas 
mentales. De este modo, el lesbianismo es rechazado en la cultura popular contemporánea. A primera vista, ambos trabajos parecen ser sensibles ante los deseos queer (momentos eróticos en el film $\mathrm{y}$ descripciones detalladas de relaciones sexuales entre personas del mismo sexo en la novela), pero al final reafirman la inevitabilidad de la heterosexualidad. Ambos autores parecen recurrir a encuentros sexuales para excitar al público/lector, siendo focos principales el voyerismo y el sensacionalismo bajo una mirada fundamentalmente heterosexual. En ambos trabajos no se nota ningún esfuerzo por comprender a sus personajes en profundidad. Las relaciones sexuales entre las dos mujeres de la película y la novela ofrecen un despliegue de erotismo y placer prohibido - Tanya y Minx toman la norma tradicional del hombre como miembro activo en la cama; mientras que Sapna y Amrita no son sólo pasivas, sino que están adormecidas o ebrias. Esto quiere decir que Sapna y Amrita no tomaron un papel activo; sino que fueron meras víctimas de la seducción de sus amigas, y se sienten culpables por haber hecho algo terrible 'una noche'.

Las zonas urbanas de la película y la novela - las áreas exclusivas de Bombay habitadas por la alta sociedad del mundo de la moda -- juegan un papel importante en cuanto a que reducen el lesbianismo a un estado de mente frívolo producido por un escenario occidentalizado, urbano y moderno. De acuerdo con Thadani (1996), el lesbianismo en el contexto social de la India se presenta al público como un producto "de liberación occidental", en lugar de asociarlo con "antiguas figuras cosmológicas prepatriarcales o con el posterior espectro autónomo de diosas Kali" (p. 93). Se sugiere que hay un rechazo incluso a reconocer la presencia inherente de sexualidades no heterosexuales en la sociedad india. Sin embargo, Ruth Vanita y Saleem Kidwai (2000), en su libro Same-Sex Love in India, utilizan el cuento sánscrito de 'El abrazo de Shiva y Vishnu' en el Bhagvata Purana para ilustrar la existencia histórica de la homosexualidad en la India. Estos cuentos procedentes de la mitología hindú muestran que instancias $y$ narrativas sobre la homosexualidad han existido en el pasado y producen un correctivo hacia declaraciones que niegan la existencia de la homosexualidad en la India.

Parece evidente que la audiencia objetivo de Girlfriend es masculina por sus numerosas escenas lésbicas eróticas ausentes de subversión y que aparecen como las elucubraciones de las dos protagonistas aparentemente heterosexuales. La primera vez que captamos el deseo de Tanya por Sapna es cuando Sapna está en la bañera y Tanya actúa de voyeur. El cuerpo de Sapna entonces funciona a dos niveles, primero "como [un] objeto erótico para [Tanya] en la historia, y [segundo] como un objeto erótico para el espectador dentro del auditórium". (NAIR, 2002, p. 54). La segunda vez que apreciamos una escena de seducción entre Tanya y Sapna es a través de flash-backs de sus días universitarios, una noche de pasión descrita vívidamente a su novio Rahul y en consecuencia, a los espectadores. Esta escena es importante por dos razones. Primero, queda claro que Razdan hace uso de la homosexualidad femenina para explotar unos fines sensacionalistas. Segundo, el personaje de Sapna tiene que ser redimida para que finalmente termine en una relación heterosexual que supuestamente le permite casarse y conseguir la bendición. La excusa dada para la indulgencia de Sapna por haber cometido ese acto es que estaba ebria y consecuentemente, fuera de sus sentidos, siendo embaucada por Tanya, quien aparece una vez más como la mujer inmoral y obsesionada con el sexo que va contra toda 
norma de convencionalidad.

La homosexualidad femenina es así usada como una estratagema erótica para atraer a los cinéfilos sensacionalistas con la promesa de escenas de desnudos a lo largo de la trama, y como mucho la explicación del sexo lésbico se atribuye a una motivación por la experimentación. Así, Razdan (2004) se las arregla para cumplir las expectativas de 'una acción seductora femenina que los espectadores esperan a la vez que se refuerza la idea de que una chica buena, consciente y sobria como Sapna nunca se desviaría del camino de la heterosexualidad'.

Shohini Ghosh (2007) hace una lectura interesante de estas secuencias de sexo, explicando que a las heroínas de las películas de Bombay se les ha atribuido con frecuencia una 'excusa' narrativa para dejarse llevar por comportamientos transgresivos, siendo la ebriedad un recurso común por el que la heroína ocupa, temporalmente, el espacio transgresivo de la mujer fatal. La segunda escena de sexo entre Tanya y Sapna se hace visible a través de lo que resultan ser las elucubraciones fóbicas de Rahul, el novio celoso. Esta larga secuencia sexual acaba con Rahul despertándose de esta 'pesadilla' y decidiéndose a 'rescatar' a Sapna de tal 'dilema'. De esta forma, la homofobia se convierte en el pretexto para la homoeroticidad. También resulta irónico que ambas escenas sexuales aparecen a través de las elucubraciones de los dos protagonistas que afirman ser heterosexuales, incluso homofóbicos, y no del personaje que es explícitamente marcada como 'lesbiana'.

También encontramos en Strange Obsession el mismo par de encuentros sexuales. Mientras Amrita está en Bombay por asuntos de su profesión como modelo, Minx disfruta de las experiencias sexuales con ella varias veces. Incluso cuando Amrita va a Delhi para ver a sus padres, Minx constantemente la persigue y la seduce en su propia casa. Minx cree firmemente que los encuentros sexuales entre personas del mismo sexo son naturales. Con respecto a esto, discute con Razdan (2004), la fotógrafa: "¿Y qué hay de anormal en mí? ¿Sólo porque sea una mujer significa que mi amor es inferior al tuyo? ¿O al de cualquier otro hombre?" (p. 163). Sin embargo, Dé (1992) no parece ser demasiado clara en este tema, ya que el mismo personaje afirma que ella no es lesbiana en absoluto: "¿abnormal? [...] Crees que soy una maldita lesbiana, ¿verdad? [...] Estás equivocada. [...] No soy tortillera. [...] No es sexual. No deseo irme a la cama contigo" (p. 32 - 33).

La definición que ofrece Tanya sobre el lesbianismo al final es extremadamente problemática. Tras su última proclamación como lesbiana, continúa diciendo que odia a los hombres y que ella misma es un chico atrapado en el cuerpo de una chica. Aquí se hace claramente un mal uso de la definición de lesbiana, tanto que la sexualidad lesbiana se construye a lo largo de la línea de la sexualidad heterosexual masculina (incluso confundiéndola con la transexualidad). Lo que implicaría esto es que las lesbianas son mujeres que desean actuar como hombres, y en este mundo de películas convencionales dominado por hombres, las relaciones lésbicas sólo pueden introducirse si responden a esta retórica, para ser condenadas posteriormente. La noción de la lesbiana como 'invertida' (un hombre atrapado en el cuerpo de una mujer) se remonta a las teorías de los sexólogos del siglo diecinueve.

Otro estereotipo excesivamente nocivo asociado a las lesbianas es que si una persona es lesbiana entonces probablemente es una trastornada mental que necesita un tratamiento que pueda 'corregir' médicamente dicho comportamiento. Tal representación juzga a Tanya como una transgresora peligrosa de la naturaleza y de la tradición 
que básicamente debe ser erradicada. Su naturaleza sexual abierta es también una amenaza para el orden heterosexual patriarcal, y por ese motivo, debe ser colocada de nuevo en su lugar 'correcto'. Tanya muere finalmente en un percance fortuito donde nadie es directamente responsable, lo cual implica que la naturaleza tiene algo que ver en esta justicia poética. El orden se recupera definitivamente con una unión heterosexual feliz entre Rahul y Sapna, de forma que la santidad del orden social queda preservada.

Películas como Girlfriend o novelas como Strange Obsession "relegan el deseo lésbico o al ámbito de lo pre-edípico (inmaduro) o al estatus de lo meramente imitativo ("Estoy buscando, como todo hombre lo haría, a una mujer")... [y] se arriesgan dejando las estructuras de heterosexualidad (y quizás heterosexismo) sin tocar" (THORNHAM, 1997, p. 123). Esto queda ejemplificado en los personajes de Tanya y Minx, quienes odian a los hombres porque sus padres abusaron de ellas durante su infancia, convirtiéndose así en hombres atrapados en el cuerpo de una mujer. Thornham (1997), citando Kristeva, afirma que la noción de "el chico atrapado en el cuerpo de una chica" tiene dos implicaciones importantes. Esto alude a la concepción de una lesbiana como "Estoy buscando, como todo hombre lo haría, a una mujer" (p. 122), representando así el lesbianismo como un modelo imitativo. El lesbianismo entonces se entiende como un concepto reductivo que puede mezclarse con otros asuntos distintos, dando lugar de este modo a una idea equivocada en relación a la definición de lesbiana o de identidad lésbica.

La homosexualidad de Tanya es vista como una patología, ya que el personaje es mostrado con la necesidad de un tratamiento médico para 'curarla'. Sue Thornham (1997) teoriza que hay una tendencia, durante el curso de la trama, a reemplazar el punto de vista [de la mujer] por un discurso masculino autoritativo. Este discurso, más frecuentemente el médico, diagnostica los "síntomas" de la protagonista femenina, sometiéndola a la "observación médica", y luego procede a devolverla a la normalidad/pasividad "curándola" (p. 53). Las bases para el tratamiento médico contra la homosexualidad también se encuentran en The History of Sexuality de Foucault (1998), donde la "categoría psicológica, psiquiátrica y médica de homosexualidad fue constituida desde el momento en que fue caracterizada" (p. 43). Esto significa que "el ámbito sexual fue $[\ldots]$ categorizado bajo la norma de lo normal y lo patológico" (p. 67) donde el dominio patológico exige "intervenciones terapéuticas o normalizadoras" (p. 68). ${ }^{4}$

Ambos textos recurren al abuso infantil para justificar el lesbianismo de Tanya y Minx. En Girlfriend, Taniya revela que abusaron de ella durante su infancia cuando trata de evitar que Sapna esté con su futura suegra. Gradualmente se transforma en una psicópata acosadora y acechadora que da rienda suelta a una violencia homicida contra Rahul. De acuerdo con la lógica aparente del film, la psicopatología de Tanya emerge no por ser una amante rechazada, sino por ser lesbiana. Es más, es lesbiana porque de niña sufrió maltrato por parte de su padre y abuso sexual por un vecino. Así, Tanya es la típica caricatura de la lesbiana que constantemente perpetúa estereotipos negativos sobre la homosexualidad femenina. Esta idea encuentra su expresión plena cuando la trama alcanza su clímax. En una secuencia que marca el nacimiento de la asesina psicopática, Tanya se corta el pelo para dejar atrás sus últimos vestigios de feminidad, mientras se enfrentaba a Rahul: "Sí... soy lesbiana, jun hombre atrapado en el cuerpo de una mujer!". Su transformación en una psicópata lesbiana se ve acompañada de una aberración corporal. Y con esto, el director del film 
confirma a una audiencia llena de prejuicios que una lesbiana no puede aspirar a nada más. $\mathrm{Su}$ odio por el sexo opuesto tiene ecos de las mismas razones dadas por Minx en Strange Obsession. Tan extraña es la obsesión de Minx por Amrita que cuando su acoso para conseguir a Amrita falla, crea una historia emocional, con el fin de ganar su confianza y compasión, en la que proyecta a su padre como violador y villano: "Escucha... Mi padre... sí, ese hombre que es tan poderoso, tan respetado, tan temido... es una bestia. Una bestia del peor tipo. Él... él... me violó".

En la mayoría de los casos se asume que a una mujer le gustan las mujeres como resultado de haber sido violadas de pequeñas y por consiguiente odian al sexo opuesto, y esto automáticamente invalida al lesbianismo como orientación sexual por derecho propio sin la existencia de dichas razones subyaciendo a las elecciones hechas por mujeres lesbianas. Al conectar el abuso sexual infantil, la criminalidad y el lesbianismo, el film y la novela catalogan a la homosexualidad como una psicopatología cuyos síntomas visibles son una obsesión predatoria y odio homicida hacia los hombres.

Dado que la cultura popular llega a la mayoría de la población e impregna el día a día en la sociedad india, el mensaje consentido que ofrecen estos autores (también altamente influido por los medios de comunicación) es este de la heteronormatividad. Ellos han popularizado imágenes estereotipadas y han comercializado en masa sus películas y novelas con las que el mundo está ya familiarizado.

Tejal Shah, un periodista y activista de los derechos humanos escribió una carta a Razdan después del estreno de la película, quejándose de tal representación homofóbica del lesbianismo:
Cada vez que oigo algo sobre un nuevo suicidio de una lesbiana, sobre otra chica que se ahorcó así misma porque su 'mejor' amiga se burló de ella, sobre una mujer hijra violada en la comisaría de policía, sobre una chica a la que mandan terapia de choque y terapia de aversión para curarla de su homosexualidad, sobre otra pareja puesta bajo arresto domiciliario por sus propios padres cuando éstos descubren que son amantes del mismo sexo, pensaré sobre esta película y me acordaré del gran poder que Bollywood ejerce al crear una consciencia de masas de una clase o de otra. En este caso, será una homofobia consciente y articulada (SHAH, 2004, n/p)

Este comentario muestra el daño, los efectos penetrantes y persuasivos de un medio tal y como el cine popular. Mientras esto no quiere decir que la audiencia/lectores sean pasivos en su valoración de los textos, ello trae consigo la triste realidad de que las parejas lesbianas tienen que encarar en el contexto de este diálogo que cualquier tipo de transgresión de la sexualidad femenina conlleva consecuencias violentas y punitivas. También muestra el punto hasta el que los textos cinematográficos y literarios se convierten en portadores de las ideologías 'dominantes'. De acuerdo con Michel Foucault (1998), el poder necesariamente no se reafirma a sí mismo a través de mecanismos de represión, censura o negación. El poder también trabaja positivamente para construir las identidades de ciertos sujetos. Por ejemplo, dice que una serie completa de discursos sobre los tipos y subtipos de homosexualidad, inversión, pederastia y "hermafrodismo psíquico" hizo posible un gran avance en el control social en este área de "perversidad", pero ello también hizo posible la formación de un discurso "inverso": la homosexualidad comenzó a hablar en su propio nombre, para demandar 
que su legitimidad o "naturalidad" fuesen conocidas, a menudo con las mismas palabras, usando las mismas categorías con las que había sido médicamente inhabilitada (p. 101).

A pesar de que hay una gran diversidad de puntos de vista queer en relación a las representaciones de la mujer lesbiana en textos culturales (cine y literatura en nuestro caso), y el tratamiento de las lesbianas en India, estos han sido totalmente ignorados por Razdan y Dé. Y lo que es más, en los debates sobre el mundo queer y lo indio, estas voces a menudo se representan en los medios de comunicación como las únicas honestas, mientras que las posiciones más complejas que se han desarrollado y articulado por otros activistas queer, ONGs y escritores o directores de películas, que no se quedan en la representación estereotipada sino que son más críticos, se les niega la atención que merecen.

Muchos teóricos han discutido el proceso de hablar por y representar a otros. Estas prácticas de representación van unidas directamente a la producción de conocimiento y poder, siendo así éticas y políticas. El hecho de que las representaciones del lesbianismo en la cultura popular india están vetadas queda claro de acuerdo con los autores analizados en este artículo. Podemos concluir diciendo que el lesbianismo o el cuerpo lésbico no es representado con responsabilidad en los textos populares bajo escrutinio en el presente artículo, ya que se encuentran dentro de los límites hegemónicos culturales y sociales. Estos textos fueron producidos y son consumidos dentro de los parámetros de la heteronormatividad y refuerzan una diversidad de estereotipos que el público voyerista es incapaz de resistir. La película Bollywoodiense Girlfriend y la novela popular Strange Obsession se mueven en la misma línea de apoyo a la ideología dominante de la heteronormatividad y presentan a la homosexualidad como una enfermedad (podríamos añadir "occidental”) que corrompe a la cultura india y que no reconoce la posibilidad de deseo entre personas del mismo sexo.

\footnotetext{
1 Traducción del inglés por Macarena Palma Gutiérrez.

2 Esta investigación ha sido financiada gracias al Ministerio de Ciencia e Innovación (Ref. FEM201018142).
}

3 Hay otra novela que trata este mismo tema, Precursor of Love de Rita Garg (2006), que condena el lesbianismo a través de la creación de tres personajes femeninos: la lesbiana femenina, que es la protagonista; Amilya, que es salvada de sus tentaciones hacia esta relación lésbica 'antinatural'; y Srishti, la lesbiana masculina. Contrario a este forzado trío, el personaje principal es el Dr. Suryanarayan, quien de gana el amor de Amilya y se casa con ella.

\begin{abstract}
$4 \quad$ Aunque "la experiencia y representación del lesbianismo en India tienen mucho en común con aquellas de hoy en día en Occidente, hay que insistir en que tal discurso sobre la medicalización de la (homo)sexualidad es específica de la Europa del siglo diecinueve. Siguiendo la regla colonial en India, la medicalización de la homosexualidad en India fue el resultado de su adaptación a las normas y regularizaciones de la época Victoriana" (VANITA, 2007, p. 246)
\end{abstract}

\section{Referencias}

DÉ, Shobhaa. Strange Obsession. New Delhi: Penguin, 1992.

FOUCAULT, Michel. The History of Sexuality: Volume One. Trans. Robert Hurley. London: Penguin Books, 1998.

GARG, Rita. Precursor of Love. New Delhi: Vishvabharti Publications, 2006.

GHOSH, Shohini. False Appearances and Mistaken Identities: The Phobic and the Erotic in Bombay Cinema's Queer Vision". 
In: BOSE, Brinda; BHATTACHARYYA, Subhabrata (Eds.). The Phobic and the Erotic: The Politics of Sexualities in Contemporary India. London: Seagull Books, 2007, p. 417 - 436.

NAIR, Bindu. Female Bodies and the Male Gaze: Laura Mulvey and Hindi Cinema. In: JAIN, Jasbir; RAI, Sudha (Eds.). Films and Feminism: Essay in Indian Cinema. New Delhi: Rawat Publishers, 2002, p. 52 - 58.

RAZDAN, Karan. Girlfriend. India: TSeries, 2004.

SHAH, Tejal. Dear Mr Razdan, homosexuals are not freaks. The Times of India. June 15, 2004.

Fonte:

$<\mathrm{http}$ ://articles.timesofindia.indiatimes.com $/ 2$ 004-06-15/india/27152852_1_deepa-mehtafilm-censor-board $>$ Acesso em 15/02/2014.

THADANI, Giti. Sakhiyani: Lesbian Desire in Ancient and Modern India. London: Cassell, 1996.

THORNHAM, Sue. Passionate Detachments: An Introduction to Feminist Theory. New York: Arnold, 1997.

VANITA, Ruth. Lesbian Studies and Activism in India. Journal of Lesbian Studies, v. 11, n. 3, p. $244-253,2007$.

VANITA, Ruth; KIDWAI, Saleem. Same Sex Love in India: Readings from Literature and History. New York: Palgrave, 2000.

Recebido em 15 de dezembro de 2013. Aceito em 03 de fevereiro de 2014. 